\title{
EFFECT OF SINGLE SESSION OF LOW-LEVEL LASER THERAPY ON PAIN, SWELLING, AND TRISMUS AFTER SURGICAL EXTRACTION OF IMPACTED LOWER THIRD MOLAR : A CLINICAL STUDY
}

\author{
Mina Kamal' ${ }^{1}$, Eman Elsharrawy ${ }^{2}$, Mohamed Hassan ${ }^{3}$
}

DOI: $10.21608 / d s u .2021 .25822 .1030$

Manuscript ID: DSU-2003-1030 (RI)

\section{KEYWORDS}

Laser, LLLT, pain,

swelling, trismus
- E-mail address: minadent88@yahoo.com.

1. Resident at Misr University of Science and Technology

2. Professor of Anesthesiology in Oral and Maxillofacial Surgery Department, Faculty of Dentistry, Suez Canal University

3. Lecturer of Oral and Maxillofacial Surgery, Faculty of Dentistry, Suez Canal University

\begin{abstract}
Introduction: Low-level laser therapy (LLLT) can promote and accelerate the tissue regeneration as it causes the early healing of extraction sockets but the accurate mechanism is unknown. Aim: The study aimed to evaluate the effect of LLLT which was applied in a single session immediately after odontectomy of impacted lower wisdom tooth on pain, swelling, and trismus. Patient and Methods: This study was done on 24 healthy patients who required surgical extraction of impacted lower third molar. The patients were randomly selected and randomly divided into two equal groups, each consisted of 12 patients for group, group I received LLLT immediately after surgical extraction of impacted lower third molar, group II was subjected to routine surgical extraction of impacted lower third molar without application of LLLT. LLLT was applied at ten points: four intra-oral beside to the extracted socket and six extra-oral along the masseter muscle. Laser energy was applied at $100 \mathrm{~mW}$ for a total of $150 \mathrm{sec}, 15 \mathrm{sec}$ for each point. Results: The results showed the effect of a single session of LLLT in control of postoperative pain on the day of surgery and reduction of swelling and trismus after surgical removal of impacted lower third molars $(\mathrm{p}<0.05)$. Conclusion: LLLT could represent a viable tool to control pain in patients who are contraindicated to the medications.
\end{abstract}

\section{INTRODUCTION}

The impacted third molar extraction is one of the most common operations in the oral cavity region leading to postsurgical complication, such as pain, swelling, and trismus. These side effects can lead to disturbances for the patients as they cause interferences with speaking and mastication ${ }^{(1)}$.

Pain usually reaches its maximum intensity from three to five hours following to the surgery, when local anesthesia action has diminished, whereas swelling mainly reaches its maximum size from twelve hours to two days later affecting the social relationship and compromising of patient esthetics ${ }^{(2)}$. The surgical trauma has been classified as the primary cause for the process of inflammation, which is associated with the postsurgical consequences ${ }^{(3)}$. Although pain and swelling gradually decrease within days after the operation, control of these complications is very critical for the doctor and the patient. 
Most surgeons have used many techniques to reduce the postoperative sequela by analgesics, non-steroidal drugs, or corticosteroids, but the side effects of these drugs cause problems for some patients who are contraindicated to these medications. Therefore, alternative approaches such as low-level laser therapy (LLLT), which is free from side effects, have represented ${ }^{(4)}$.

Low-level laser therapy, which is diode laser energy application near to infrared wavelengths ${ }^{(5)}$, has been considered to have actions on accelerating of the rate of healing, decreasing of the level of pain, and promoting of the process of inflammation. Due to these functions, Low-level laser therapy has been applied in different dental treatments such as reducing of the side effects of teeth extraction ${ }^{(6)}$. Low-level laser therapy can also be used to promote and accelerate bone regeneration as it causes the early healing of extraction sockets ${ }^{(7)}$.Low-level laser therapy can have both bio-stimulatory and bioinhibitory effects on irradiated tissues where each of them can have therapeutic applications. Laser therapy is dependent on biologic response induction through energy transfer ${ }^{(8)}$. The principle behind the application of LLLT is light energy application with bio modulatory capacity on body cells ${ }^{(9)}$. Cytochrome c oxidase can absorb low-level laser irradiation and transfer it inside mitochondria to provide cell energy in the form of adenosine diphosphate (ATP) which is the product of cytochrome c oxidase and Krebs cycle. The stimulation of ATP synthesis leads to an increase in cell activity.

\section{PATIENTS AND METHODS}

The study was done on healthy patients from the outpatient clinic of Oral and Maxillofacial Surgery Department, Faculty of Dentistry, Suez Canal University who required surgical extraction of impacted lower third molar. Sample size was calculated by using STATA version 11 program, setting the type- 1 error $(\alpha)$ at 0.05 and power at $80 \%$. According to values of a previous study, the needed sample was twenty-four cases. Twentyfour patients with lower impacted third molar that need surgical extraction were selected and divided randomly into two equal groups; 12 patients for each group. Group (I): received LLLT immediately after odontectomy of impacted lower third molar. Group (II): subjected to routine odontectomy of impacted lower third molar without application of LLLT. All patients were informed about the aim of study, details of the surgical procedures, the expected complications, possible side effects of the used drugs, and signed a written informed consent. Digital panoramic radiograph was done before odontectomy of impacted lower third molar to evaluate depth and angulations of the impaction.

All the surgical procedures were done under strict aseptic condition by the same surgeon. Inferior alveolar, lingual, and long buccal nerve block techniques were used. Local anaesthesia was injected by using mepivacaine hydrochoride $2 \%$ with levonordefrin 1:20,000 as a vasoconstrictor presented in carpule $1,8 \mathrm{ml}$ with a trade name Mepecaine-L (Alexandria Co. for Pharmaceuticals. Alexandria, Egypt). According to position of impacted tooth, the incision was done. After that, Reflection of full mucoperiosteal flap was made. Then, Removal of bone was done around the impacted tooth under warm saline irrigation. The irrigation was done during the surgical procedures by using warm saline to hydrate the dehydrated cells. Curettage of the socket was done by using bone curette for removal of granulation tissue or debris in the socket after the tooth delivery. The flap was closed by using 3-0 black silk suture. The sutures were taken off after one week of the operation.

All patients in both groups were subjected to the following drugs after the surgery: Amoxicillin with Clavulanic acid available as $1 \mathrm{gm}$ tablets every $12 \mathrm{~h}$ for 7 days (Augmentin is produced by medical 
union pharmeceuticals, Abu Suiltan, Ismailia under license from the GlaxoSmithKline group of companies). Metronidazole is available as $500 \mathrm{mg}$ tablet every $12 \mathrm{~h}$ for 7 days. Ibuprofen available as $400 \mathrm{mg}$ tablets as required (Brufen is manufactured by Kahira Pharma \& Chemical Ind. Co. under license of Abbott Laboratories). Chlorhexidine antiseptic mouth wash available as $15 \mathrm{ml}$ of $0.12 \%$ Chlorhexidine mouth wash every $12 \mathrm{~h}$ for one week after the surgery(produced by The Arab Drug Company, Cairo, A.R.E).

Immediately after surgery, patients of group (I) were subjected to one session of low-level laser therapy by diode laser device (Doctor Smile Wiser diode laser $16 \mathrm{~W} 980 \mathrm{~nm}$ model LA8D0001.3). Laser energy was intra-orally and extra-orally administered with $100 \mathrm{~mW}$ power output at continuous mode of $980 \mathrm{~nm}$ wavelength. Laser energy was applied by use of the biostimulation contact tip. Tip diameter of the handpiece was $1 \mathrm{~cm}$ with contact mode. Following the surgery, single dose of laser energy was administered at four intra-oral points and six extra-oral points. Positions of the intra-oral points were around the extraction socket on the buccal, distal, lingual, and mesial parts of wound. Positions of extra-oral points were along the masseter muscle, two on the origin, two on the insertion, and two at the middle length of the muscle. Laser energy was applied at $100 \mathrm{~mW}$ for a total of $150 \mathrm{sec}, 15 \mathrm{sec}$ for each point, $0.1 \mathrm{~W} \times 150 \mathrm{~s}=15 \mathrm{~J}$.

The pain level was recorded by using of the visual analog scale. The pain level was recorded when the patient need to take analgesic tablets after the surgery. Preoperative assessment of the facial contour was measured as four points marked on skin surface: ear tragus, corner of the mouth, angle of the lower jaw, and outer canthus of the eye. The facial contour was recorded in $(\mathrm{cm})$ by measuring the two distances between ear tragus and lip corner, mandible angle and outer canthus. The average of the sum of two distances was considered as the baseline measurement ${ }^{(10)}$.The maximum opening of the oral cavity was recorded in $(\mathrm{mm})$ by use of the digital caliper. The measurements were at the maximum interincisal distance between the maxillary and the mandibular central incisors. The measurements of swelling and trismus were repeated after 2 and 7 days of surgery by measuring the same distances as we described in the preoperative assessment.

All data were collected and coded then assessed by use of SPSS statistical analysis program. Data were presented as mean \pm standard deviation. Wilcoxon Signed Ranks test for repeated measurements was used to compare pre-operative and post-operative data. A p-value of $<0.05$ was considered statistically significant.

\section{RESULTS}

Postoperatively, one patient (group I) developed acute inflammatory reaction at area of surgery which was managed by antibiotic therapy in addition to another patient (group II) developed acute alveolitis and treated with local and systemic treatment. There were no significant differences between the two groups relating to age, sex, and the type of impaction.( Table 1)

Table 1: Patients distribution of according to age, sex, and impaction type

\begin{tabular}{|c|c|c|c|c|}
\hline \multicolumn{2}{|c|}{} & Group I & Group II & P-value \\
\hline Age (years) & $($ Mean \pm SD) & $25.4 \pm 3.8$ & $26.2 \pm 3.2$ & 0.231 \\
\hline \multirow{2}{*}{ Sex } & Female & 7 & 7 & \multirow{2}{*}{1.00} \\
\cline { 2 - 5 } $\begin{array}{c}\text { Type of } \\
\text { impaction }\end{array}$ & Male & 5 & 5 & \\
\cline { 2 - 4 } & Distoangular & 2 & 1 & \multirow{2}{*}{1.00} \\
\cline { 2 - 5 } & Mesioangular & 5 & 4 & \\
\cline { 2 - 5 } & Vertical & 1 & 2 & \\
\hline
\end{tabular}


On comparing the two groups together, it was found statistically insignificant change in VAS scores at all days after the surgery except the day of surgery. On the day of surgery, mean pain score was higher in group (II) compared to group (I). There were significant changes in pain score compared the two groups together as it was $6.3 \pm 1.19$ in group (I) and $7 \pm 1.04$ in group (II) (P-value $=0.031)$ in addition to four patients in the group I did not need to take analgesics. After one day of surgery, pain score decreased as it was $5.1 \pm 1.9$ in the group (I) and $6 \pm 1.48$ in the group (II) $(\mathrm{P}$-value $=0.384)$. After two days of the surgery, pain score decreased as it was $4 \pm 2.2$ in group (I) and $4.7 \pm 1.97$ in group (II) (P-value $=0.446)$. After three days of the surgery, pain score decreased as it was $2.2 \pm 2.06$ in group (I) and $2.7 \pm 1.50$ in group (II) (P-value = 0.461). (Figure 1)

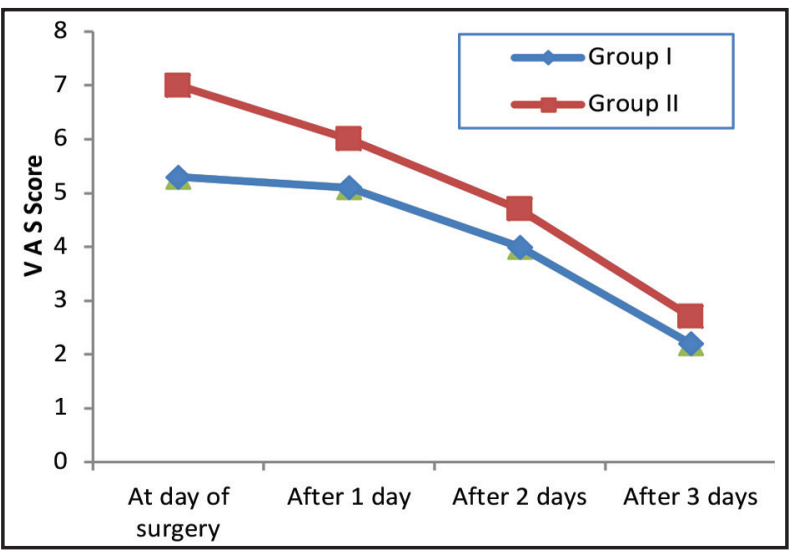

Fig. (1) Postoperative changes of VAS score in both groups

After 2 days of the surgery, there were a statistically significant differences in the mean facial contour measurement between the two groups as it was $11.0 \pm 0.5 \mathrm{~cm}$ in group (I) and $12.1 \pm$ $0.6 \mathrm{~cm}$ in group (II) where P-value $=0.028$. The same result was monitored after 7 days of surgery through which there was a statistically significant differences in the mean facial contour measurement between the two groups as it was $10.6 \pm 0.4 \mathrm{~cm}$ in group (I) and $11.4 \pm 0.5 \mathrm{~cm}$ in group (II) where $\mathrm{P}$-value $=0.028$. $($ Figure 2$)$

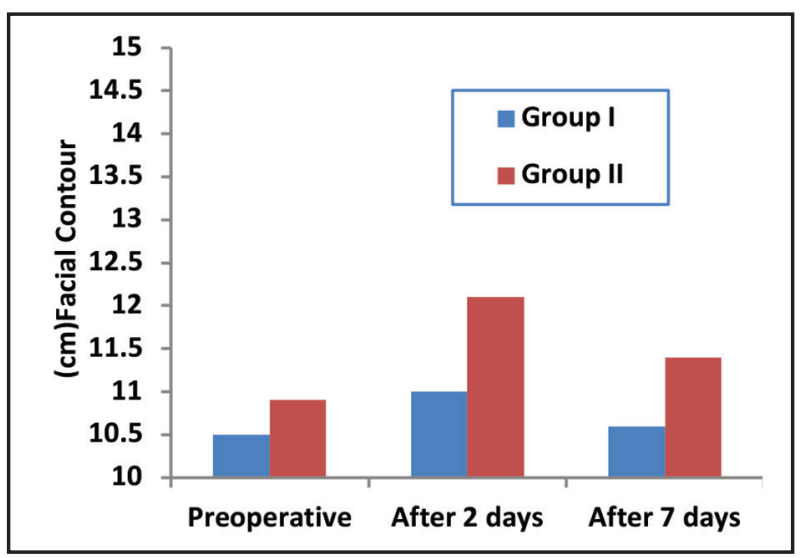

Fig. (2) Swelling in both groups

After 2 days of the surgery, there was statistically significant difference in mouth opening between the two groups as it was $33.2 \pm 10.1 \mathrm{~mm}$ in group (I) and $30.9 \pm 4.3 \mathrm{~mm}$ in group (II) where P-value $=$ 0.035 . Also, after 7 days of the surgery, there was statistically significant difference in mouth opening between the two groups as it was $44.5 \pm 8.0 \mathrm{~mm}$ in group (I) and $41.2 \pm 4.9 \mathrm{~mm}$ in group (II) where $\mathrm{P}$-value $=0.031 .($ Figure 3$)$

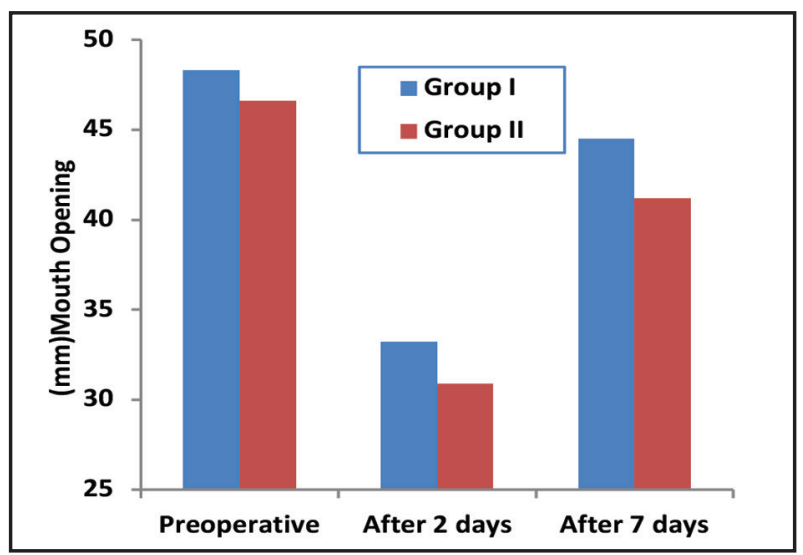

Fig. (3) Trismus in both groups 


\section{DISCUSSION}

The effect of biostimulation of LLLT is controversial because the constant parameters of physical and biological variables of the laser that used in a previous study are absent. For instance, laser type, pulse frequency, power output, application time and wavelength can lead to difficulties in the investigations ${ }^{(11)}$. Therefore, up-till now, the parameters of optimal LLLT for biostimulation are unclear ${ }^{(12)}$.

The present study was in agreement with studies of Landucci et al. ${ }^{(13)}$ and Clokie et al $^{(14)}$ who applied a single dose of LLLT for one and three minutes wavelength respectively immediately after surgical extraction of lower third molar. They reported significant reductions in pain level postoperatively ( $\mathrm{P}$ $<0.05)$. On the other hand, Amarillas et al. ${ }^{(3)} \mathrm{dem}-$ onstrated LLLT effect after odontectomy of impacted third molars. The study group received intra-oral and extra-oral LLLT to evaluate the pain for 7 days after odontectomy of impacted lower third molars. The postoperative pain was reduced without statistically significant differences ( $\mathrm{P}<0.001)$. Batinjan et $a l .{ }^{(15)}$ reported that use of intraoral soft laser once immediately after third molar extraction had significant reduction in pain and wound temperature in addition to better wound healing.

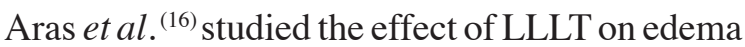
and trismus after surgical extraction of lower third molars when laser applied intra-orally and extraorally. Forty-eight patients were divided into three equal groups as follows: extra-oral application, intra-oral application, and placebo. They applied laser energy at $100 \mathrm{~mW}$. Swelling and trismus were evaluated at 2 days and 7 days postoperatively. It was reported that extra-oral laser application had a significant effect on swelling and trismus $(\mathrm{P}<0.05)$.

The study was in agreement with Ferrante et $a l .{ }^{(17)}$ who used $980 \mathrm{~nm}$ diode laser at continuous mode with $300 \mathrm{~mW}$ for a total of $180 \mathrm{sec}$. The laser was applied intra-orally and extra-orally immediately and after 1 day of surgical extraction of lower wisdom tooth. Swelling was evaluated at the second and the seventh postoperative days. Ferrante reported significant reductions in postoperative swelling $(\mathrm{P}<0.05)$.

On the other hand, the study by Aras et al. ${ }^{(16)}$ showed that no decrease in the swelling with intraoral laser application only. Comparatively, the extraoral laser can be directly applied to the masseter muscle insertion. This could be the reasons why some studies obtained positive results in decreasing of mouth opening limitation when application of extra-oral was used ${ }^{(18)}$. Some authors ${ }^{(19)}$ reported that LLLT cannot help in reduction of swelling and trismus after odontectomy of wisdom teeth. In all of these studies, the authors applied only intra-oral laser with different parameters. This is in contrast to Markovic et al. ${ }^{(20)}$ who reported that intra-oral LLLT significantly decreased swelling and trismus.

\section{CONCLUSION}

The outcome of results showed the usefulness of a single session of LLLT in reduction of pain, edema, and trismus after odontectomy of impacted lower third molar. We suggest that LLLT could represent a viable tool to control pain in patients who are contraindicated to the medications.

\section{REFERENCE}

1. Lopez-Ramirez M, Vilchez-Perez MA, Gargallo-Albiol J, Arnabat-Dominguez J. Efficacy of low-level laser therapy in the management of pain, facial swelling, and postoperative trismus after a lower third molar extraction. A preliminary study. Lasers Med Sci 2012;27:559-566.

2. Larrazabal C, Garcia B, Penarrocha M, Penarrocha M. Influence of oral hygiene and smoking on pain and swelling after surgical extraction of impacted mandibular third molars. J Oral MaxillofacSurg 2010;68:43-46. 
3. Amarillas-Escobar ED, Toranzo-Fernandez JM, MartinezRider R, Hidalojo-Hurtado JA, Gordillo-Moscoso A, Pozos-Guillen AJ. Use of therapeutic laser after surgical removal of impacted lower third molars. J Oral Maxillofac Surg 2010;68:319-324.

4. Kumar N, Prasad K, Ramanujam L, Dexith J, Chauhan A. Evaluation of treatment outcome after impacted mandibular third molar surgery with the use of autologous plateletrich fibrin: A randomized controlled clinical study. J Oral Maxillofac Surg 2015;73:1042-1049.

5. Niemz MH. Laser-Tissue Interactions: Fundamentals and Applications. Niemz MH. Interaction Mechanisms. 3rd ed., Springer; 2004:45-150

6. He WL, Yu FY, Li CJ, Pan J, Zhuang R, Duan PJ. A systematic review and meta-analysis on the efficacy of low-level laser therapy in the management of complication after mandibular third molar surgery. Lasers Med Sci 2015;30:1779-1788.

7. Vladimirov YA, Osipov AN, Klebanov GI. Photobiological principles of therapeutic applications of laser radiation. Biochemistry (Mosc) 2004;69:81-90.

8. Parker S. Low-level laser use in dentistry. Br Dent $\mathbf{J}$ 2007;10:131-138.

9. Mohkovska T, Mayberry J. It is time to test low level laser therapy in Great Britain. Postgrad Med J 2005;81:436-441.

10. Sun G, Tuner J. Low-level laser therapy in dentistry. Dent Clin North Am 2004;48:1061-1076.

11. Amin MM, Laskin DM. Prophylactic use of indomethacin for prevention of postsurgical complications after removalof impacted third molars. Oral Surg Oral Med Oral Pathol 1983;55:448-451.

12. El-Soud NA, Shenawy HE. A randomized double blind clinical study on the efficacy of low level laser therapy in reducing pain after simple third molar extraction. Maced $\mathbf{J}$ Med Sci 2010 15;3:303-306.
13. Landucci A, Wosny AC, Uetanabaro LC, Moro A, Araujo MR. Efficacy of a single dose of low-level laser therapy in reducing pain, swelling, and trismus following third molar extraction surgery. Int $\mathbf{J}$ Oral Maxillofac Surg 2016;45:392-398.

14. Clokie C, Bentley KC, Head TW. The effects of the helium-neon laser on postsurgical discomfort: a pilot study. J Can Dent Assoc 1991;57:584-586.

15. Batinjan G, Zore Z, Čelebić A, Papić M, Gabrić Pandurić D, Filipović Zore I. Thermographic monitoring of wound healing and oral health-related quality of life in patients treated with laser (aPDT) after impacted mandibular third molar removal. Int J Oral Maxillofac Surg 2014;43:1503-1508.

16. Aras MH, Gungormus M. Placebo-controlled randomized clinical trial of the effect two different low-level laser therapies (LLLT) intraoral and extraoral on trismus and facial swelling following surgical extraction of the lower third molar. Lasers Med Sci;2010;25:641-645.

17. Ferrante M, Petrini M, Trentini P, Perfetti G, Spoto G. Effect of low-level laser therapy after extraction of impacted lower third molars. Lasers Med Sci 2013;28:845-849.

18. Kazancioglu HO, Ezirganli S, Demirtas N. Comparison of the influence of ozone and laser therapies on pain, swelling, and trismus following impacted third-molar surgery. Lasers Med Sci 2014;29:1313-1319.

19. Aras MH, Gungormus M. The effect of low-level laser therapy on trismus and facial swelling following surgical extraction of the lower third molar. Photomed Laser Surg 2009;27:21-24.

20. Markovic AB, Todorovic L. Postoperative analgesia after third molar surgery: contribution of the use of longacting local anaesthetics, low-power laser and diclofenac. Oral Surg Oral Med Oral Pathol Oral Radiol Endod 2006;102:4-8. 